\title{
Characterizing endophytic competence and plant growth promotion of bacterial endophytes inhabiting the seed endosphere of Rice
}

Denver I. Walitang ${ }^{1}$, Kiyoon Kim ${ }^{1}$, Munusamy Madhaiyan ${ }^{2}$, Young Kee Kim', Yeongyeong Kang ${ }^{1}$ and Tongmin $\mathrm{Sa}^{{ }^{1 *}}$

\begin{abstract}
Background: Rice (Oryza sativa L. ssp. indica) seeds as plant microbiome present both an opportunity and a challenge to colonizing bacterial community living in close association with plants. Nevertheless, the roles and activities of bacterial endophytes remain largely unexplored and insights into plant-microbe interaction are compounded by its complexity. In this study, putative functions or physiological properties associated with bacterial endophytic nature were assessed. Also, endophytic roles in plant growth and germination that may allow them to be selectively chosen by plants were also studied.

Results: The cultivable seed endophytes were dominated by Proteobacteria particularly class Gammaproteobacteria. Highly identical type strains were isolated from the seed endosphere regardless of the rice host's physiological tolerance to salinity. Among the type strains, Flavobacterium sp., Microbacterium sp. and Xanthomonas sp. were isolated from the salt-sensitive and salt-tolerant cultivars. PCA-Biplot ordination also showed that specific type strains isolated from different rice cultivars have distinguishing similar characteristics. Flavobacterium sp. strains are phosphate solubilizers and indole-3-acetic acid producers with high tolerance to salinity and osmotic stress. Pseudomonas strains are characterized as high siderophore producers while Microbacterium sp. and Xanthomonas sp. strains have very high pectinase and cellulase activity. Among the physiological traits of the seed endophytes, bacterial pectinase and cellulase activity are positively correlated as well as salt and osmotic tolerance. Overall characterization shows that majority of the isolates could survive in $4-8 \%$ salt concentration as well as in $0.6 \mathrm{M}$ and $1.2 \mathrm{M}$ sucrose solution. The activities of catalase, pectinase and cellulase were also observed in almost all of the isolates indicating the importance of these characteristics for survival and colonization into the seed endosphere. Seed bacterial endophytes also showed promising plant growth promoting activities including hormone modulation, nitrogen fixation, siderophore production and phosphate solubilization.

(Continued on next page)
\end{abstract}

\footnotetext{
* Correspondence: tomsa@chungbuk.ac.kr

${ }^{1}$ Department of Environmental and Biological Chemistry, College of

Agriculture, Life and Environmental Sciences, Chungbuk National University,

Cheongju, Chungbuk 28644, Republic of Korea

Full list of author information is available at the end of the article
}

\section{Ciomed Central}

(c) The Author(s). 2017 Open Access This article is distributed under the terms of the Creative Commons Attribution 4.0 International License (http://creativecommons.org/licenses/by/4.0/), which permits unrestricted use, distribution, and reproduction in any medium, provided you give appropriate credit to the original author(s) and the source, provide a link to the Creative Commons license, and indicate if changes were made. The Creative Commons Public Domain Dedication waiver (http://creativecommons.org/publicdomain/zero/1.0/) applies to the data made available in this article, unless otherwise stated. 
(Continued from previous page)

Conclusion: Though many of the isolates possess similar PGP and endophytic physiological traits, this study shows some prominent and distinguishing traits among bacterial groups indicating key determinants for their success as endophytes in the rice seed endosphere. Rice seeds are also inhabited by bacterial endophytes that promote growth during early seedling development.

Keywords: Endophytic competence, Plant growth promotion, Physiological characterization, Rice seeds, Bacterial endophytes

\section{Background}

Plant-microbe interactions have important advantages especially concerning beneficial bacteria. Plants are internally inhabited by plant-associated bacteria, known as endophytes, which directly influence the host plant cells mediating responses as a result of interactions [1] without damaging the host or eliciting strong defense responses [2]. As the plant endosphere niche presents a unique habitat, bacterial endophytes are likely to have differential functions, specialization, adaptations and competence $[3,4]$. Furthermore, it is likely that only specialized endophytic strains are capable of colonizing and surviving in the reproductive plant organs $[3,5]$ and that only bacteria with competitive and adaptive colonization characteristics could inhabit the seeds [4]. Metagenomic analysis of sequences from bacterial endophytes of rice roots predicted properties and metabolic processes important for endophytic lifestyle. These include prominent features such as flagella or motility mechanism, plantpolymer degrading enzymes, protein secretory systems, iron chelation, acquisition and storage, quorum sensing, ROS detoxification, and other characteristics probably involved in the entire nitrogen cycle [6]. Furthermore, comparative genomics of traits relevant to plant colonization and establishment of symbionts, phytopathogens, rhizosphere bacteria and soil bacteria show that there are putative properties that are significantly observed in endophytes compared to other types of bacteria interacting with plants [7] confirming those features studied by Sessitsch et al. [6].

Despite differences in ecological niches, plant growthpromoting rhizobacteria (PGPR) that are free-living and endophytic bacteria utilize some of the same mechanisms to directly and indirectly promote plant growth [8-10]. Plant hosts, on the other hand, may also confer a selective advantage over endophytes that show beneficial associations. As bacteria develop beneficial interactions with plants, they are able to enhance growth and yield, suppress pathogens, and mobilize some micronutrients [11]. Hardoim et al. [7] added that bacterial endophytes also possess other plant growth promoting abilities such as nitrogen fixation, phosphate solubilization and iron chelation. The seeds are also shown to be sources of endophytic bacteria of the rice plant [12] and that rice seed bacterial endophytes rapidly colonize the roots then the shoots of developing rice plants [13] indicating their endosphere competence in terms of colonization, survival and even transmission to the next generation hosts. Mano and Morisaki [14] also observed that the bacterial flora of the seeds is closer to that of the shoots than to those of the roots supporting the results of Hardoim et al. [13]. The communities of rice bacterial endophytes were also seen to actively respond to the changes in the environmental conditions of their host [13] and that bacterial adaptation as well as plant host factors affect the overall community structure of endophytes residing in different rice cultivars [15].

There have been numerous reports on indigenous endophytic bacteria in various plants and plant tissues. However, studies on bacterial endophytes inhabiting rice seeds together with their putative endophytic functional traits and plant growth promotion are few most especially on specific cultivars that are anthropogenically selected based on their potential commercial or special applications. Thus, the purpose of this study was to investigate the endophytic bacterial floras in the different salt-sensitive and tolerant rice cultivars. Also, some prominent features of putatively known functions associated with bacterial endophytic nature that confer an advantage for colonization and survival in the seeds were investigated. In addition, the roles of seed endophytes in germination and plant growth promotion (PGP) that may allow them to be selectively chosen by plants were also studied.

\section{Methods \\ Seed samples}

All seeds used in this study were taken from Rural Development Administration (RDA), South Korea. Seed germination started in May and seedling transplantation was done in June. There were five salt-tolerant cultivars included namely IR669646-3R-178-1-1 (FL478), CSR 28 (IC27), IR55179-3B-11-3 (IC31), IR58443-6B-10-3 (IC32), IRRI154 (IC37), and a salt-sensitive cultivar (IR29). The salt-tolerant cultivars: IC27, IC31, IC32 and IC37 are experimental hybrid lines being studied for their salinity tolerance. IR29 is a sodium accumulating line that is salt-sensitive during early and mature plant growth development. FL478 is a hybrid from the salt-sensitive line IR29 and a salt-tolerant sodium excluding Pokkali B [16]. IC27 and IC31 have one common parent, IR4630-22-2-5-1-3 which is also distantly related 
to Pokkali. One of the parents of IC32 could also be traced to Pokkali. The highly salt-tolerant cultivar, IC37, has parental lines different from the other cultivars. All cultivars in this study belong to Oryza sativa ssp. indica. All the seed samples were harvested from August to early September (Table 1). All seeds used for bacterial isolation were fresh. Seeds were also stored at $4{ }^{\circ} \mathrm{C}$ without any seed treatment for further use.

\section{Surface sterilization of seeds}

Bacterial communities of the rice seed endosphere were assessed by culture-dependent approaches. Surface sterilization of rice seeds was done according to Hardoim et al. [13]. Under sterile conditions, decontaminated forceps were used to remove the hulls of rice seeds $(1 \mathrm{~g})$. Subsequent surface-sterilization was done at $30{ }^{\circ} \mathrm{C}$ for $25 \mathrm{~min}$ in an orbital shaker (200 rpm) with a $50 \mathrm{ml}$ solution containing $0.12 \%$ sodium hypochlorite $(\mathrm{NaClO})$ and salts $(0.1 \%$ sodium carbonate, $3 \%$ sodium chloride, and $0.15 \%$ sodium hydroxide) [17]. Removal of the surface adhered $\mathrm{NaClO}$ was achieved by washing with $50 \mathrm{ml} 2 \%$ sodium thiosulfate [18] repeated twice at $30{ }^{\circ} \mathrm{C}$ for $10 \mathrm{~min}$ under orbital shaking $(200 \mathrm{rpm})$. The seeds were rinsed 5-8 times with sterile distilled water before the seeds were subjected to rehydration for at least $1 \mathrm{~h}$ at room temperature in $100 \mathrm{ml}$ autoclaved demineralized water. The efficiency of sterilization was confirmed by plating $100 \mu \mathrm{L}$ of the final rinse onto $\mathrm{R} 2 \mathrm{~A}$ agar plates and incubating them for 7 days at $28^{\circ} \mathrm{C}$.

\section{Culturable bacterial population}

Surface sterilized seeds were ground with an autoclaved mortar and pestle. Culturable populations of seed endophytic bacteria were determined by counting the colony forming units (CFU) on R2A (DB - Difco) plates using spread plate technique after serial dilution of the homogenized surface sterilized seed samples $(1.0 \mathrm{~g})$. Ten-fold serial dilutions were made and $100 \mu \mathrm{l}$ aliquots were spread onto an R2A agar in three replicates for each dilution. Plates were incubated at $28{ }^{\circ} \mathrm{C}$. For bacteria population, counting was done every $24 \mathrm{~h}$ for 6 days. Unique bacteria from each plate were chosen based on colony color and morphology. Identification of the bacterial isolates was done through $16 \mathrm{~S}$ rRNA gene sequence analysis.

\section{S rRNA gene sequence analyses}

Pure cultures of endophytic bacteria were subjected to $16 \mathrm{~S}$ rDNA sequence analysis. Isolates were grown on nutrient agar plates. Genomic DNA was extracted and PCR was used to amplify the 16S rRNA genes using the primers 27F: 5'-AGA GTT TGA TCC TGG CTC AG$3^{\prime}$ as the forward primer and 1492R: $5^{\prime}{ }^{\prime}$ GTT TAC CTT GTT ACG ACT T-3' as the reverse primer [19] followed by identification of the 16S rRNA nucleotide sequences using PCR-direct sequencing, via the fluorescent dye terminator method (ABI Prism ${ }^{\mathrm{Tu}}$ Bigdye $^{\mathrm{Tn}}$ Terminator cycle sequencing ready reaction kit v.3.1). The products were purified using Millipore-Montage dye removal kit and ran in an ABI3730XL capillary DNA sequencer with a $50 \mathrm{~cm}$ capillary. The obtained $16 \mathrm{~S}$ rDNA sequences were aligned and the affiliations deduced using BLAST analysis in the EzTaxon server (https://www.ezbiocloud.net/) [20]. Phylogenetic analyses were performed using MEGA version 6 [21] after multiple alignments of the data by CLUSTAL W [22]. DNA substitutions were done according to the Jukes and Cantor model [23] and clustering was performed using the neighbor-joining method [24]. The statistical confidence of the nodes was estimated by bootstrapping using 1000 replications [25]. The nucleotide sequences of $16 \mathrm{~S}$ rRNA genes were deposited to the GenBank $^{\circ}$ database under accession numbers KY393309-KY393357.

\section{Screening of PGP characteristics}

Production of indole-3-acetic acid (IAA) by the isolates was quantified in the presence and absence of tryptophan [26]. Filter sterilized tryptophan was supplied in the medium at a concentration of $500 \mu \mathrm{g} \mathrm{ml}^{-1}$. The ability to solubilize phosphate (tricalcium phosphate) was carried out in NBRIP-BPB plates [27]. Siderophore production was studied on CAS agar plates prepared according to Alexander and Zuberer [28]. ACC deaminase (1-aminocyclopropane1-carboxylate deaminase; ACCD) activity was determined by growing the bacterial isolates in nitrogen-free medium

Table 1 Characteristics of the six (6) rice cultivars (Oryza sativa L. ssp. indica) used to assess bacterial community associated with the seeds

\begin{tabular}{|c|c|c|c|c|c|}
\hline \multirow[t]{2}{*}{ Rice Cultivar } & \multirow[t]{2}{*}{ Parental Lines } & \multirow[t]{2}{*}{ Harvest Date } & \multirow{2}{*}{$\begin{array}{l}\text { Stem Height } \\
\mathrm{cm}\end{array}$} & \multicolumn{2}{|c|}{ Salinity Tolerance } \\
\hline & & & & Early growth & Mature plant \\
\hline IR29 & IR833-6-2-1-1 | 11 (1561-149-1)//1R1737 & 21 August 2014 & 78 & Weak & Weak \\
\hline $\mathrm{FL478}$ & IR29/POKKALI B & 18 August 2014 & 61 & Strong & Moderate \\
\hline IC27 & IR42/IR 4630-22-2-5-1-3 & 05 September 2014 & 82 & Moderate & Moderate \\
\hline IC31 & IR 4630-22-2-5-1-3/NONA BOKRA & 15 August 2014 & 71 & Strong & Moderate \\
\hline IC32 & AT 401/IR31868-64-2-3-3-3 & 18 August 2014 & 69 & Strong & Moderate \\
\hline IC37 & IR 73012-137-2-2-2/PSB RC 10 (IR 50404-57-2-2-3 & 22 August 2014 & 67 & Strong & Strong \\
\hline
\end{tabular}

Source: International Rice Research Institute, Philippines (IRRI); Rural Development Administration, Korea (RDA) 
amended with $3 \mathrm{mM}$ ACC as nitrogen source [29] and the amount of $\alpha$-ketobutyrate produced by the enzymatic hydrolysis of ACC was estimated following Honma and Shimomura [30]. Nested PCR was performed to amplify nifH gene in bacterial endophytes. For the first PCR, PolF/ PolR primer set was used, whereas for the nested PCR, nifHFor and nifHRev primer set was used according to Soares et al. [31].

\section{Rice seed germination with and without salt stress and early seedling development}

Rice seeds, Oryza sativa L. ssp. indica 'IR29' were surface sterilized as described above. Aliquots $(100 \mu \mathrm{l})$ of water from the final wash were spread on R2A to ensure efficiency of sterilization. Seed treatments consisted of soaking surface sterilized seeds in sterile media $\left(0.03 \mathrm{M} \mathrm{MgSO}_{4}\right)$ or late log phase cultures of the isolates for $4 \mathrm{~h}$. At the end of seed treatments, 30 seeds were transferred to each petri plate containing sterile filter papers moistened with $10 \mathrm{ml}$ distilled water and treatments were maintained in triplicates. The plates were then moved to a plant growth chamber maintained at $25 \pm 2{ }^{\circ} \mathrm{C}$ under $12 \mathrm{~h} / 12 \mathrm{~h}$ dark/light conditions. Seed germination was checked every $24 \mathrm{~h}$ for 5 days. Additionally, germination tests under $150 \mathrm{mM}$ salt solution with sterile distilled water acting as a control were also conducted. In another set of experiments, treated and non-treated rice seeds were germinated in the same conditions as above. After 2 days, 5 fully germinated seeds were transferred into a moist sterile plant pouch and allowed to continue growing up to 7 days. Root and shoot length as well as wet and dry weights were measured at the end of the experiment.

\section{Characterization and putative endophytic adaptations of seed bacterial isolates}

The strains were initially checked for Gram reaction and colony characteristics, and characterization for oxidase and catalase activities were done following standard methods. The intrinsic resistance of the bacterial isolates against salinity was evaluated by observing growth on NA medium (Nutrient broth - Merck) amended with a final concentration of $\mathrm{NaCl}(2,4,6,8 \% w / v)$. The plates were incubated for $3-5$ days at $28 \pm 2{ }^{\circ} \mathrm{C}$. The same experiment was carried out with $\mathrm{NaCl}$ amended nutrient broth and OD was recorded after 3 days of incubation. Osmotic tolerance of the bacterial isolates was also evaluated in $5 \mathrm{ml} \mathrm{NB}$ broth amended with $0.6 \mathrm{M}$ [12] and $1.2 \mathrm{M}$ [4] sucrose and bacterial growth was measured at $540 \mathrm{~nm}$ after 3 days of incubation. Motility of bacteria was observed in semi-solid media prepared according to Tittsler and Sandholzer [32] and modified with $0.005 \%$ 2,3,5-triphenyltetrazolium chloride. Cellulase test was studied on carboxymethycellulose (CMC) plates prepared according to Kasana et al. [33] while pectinase activity was studied according to Jacob et al. [34]. Cellulase and pectinase activity were both visualized using Gram's iodine.

\section{Genetic diversity by BOX-PCR}

Genomic DNA of endophytic bacteria isolated from the seed endosphere of different rice cultivars was amplified directly using colony PCR or by isolating genomic DNA using genomic isolation kit (Promega, USA). The primer used for the BOX-PRC reaction was BOX-AIR ( $5^{\prime}$ CTACGGCAAGGCGACGCTGACG-3') as described by Naik et al. [35]. Each reaction contained $2 \mu \mathrm{L}$ of $10 \mathrm{mM}$ dNTP, $2 \mu \mathrm{L}$ of 10X PCR buffer, $2 \mu \mathrm{L}$ of 10 pmol BOXAIR primer, $0.2 \mu \mathrm{L}$ Taq polymerase and MilliQ water adjusted to a total volume of $20 \mu \mathrm{L}$. Amplification was performed in a PTC200 DNA Thermal Cycler (MJ Scientific, USA) using the following program: $95{ }^{\circ} \mathrm{C}$ for $5 \mathrm{~min}$ for colony PCR and $3 \mathrm{~min}$ for genomic DNA, $30 \times\left(94{ }^{\circ} \mathrm{C}\right.$ for $3 \mathrm{~s}, 92{ }^{\circ} \mathrm{C}$ for $30 \mathrm{~s}, 50{ }^{\circ} \mathrm{C}$ for $1 \mathrm{~min}, 65^{\circ} \mathrm{C}$ for $8 \mathrm{~min}$ ), and a final extension of $65^{\circ} \mathrm{C}$ for $8 \mathrm{~min}$. Hierarchical cluster analysis was performed using IBM SPSS version 20.

\section{Statistical analysis}

Randomized block design was used for seed germination and early growth development. Data from the results were normalized, subjected to analysis of variance (ANOVA) and mean significant difference were compared using least significant difference (LSD) at $P \leq 0.05$ using SAS version 9.1 package (SAS Institute Inc., Cary, NC, USA). Data from PGP traits and physiological activities were used to generate the biplot ordination diagram of principal component analysis with Primer V.6.

\section{Results}

\section{Cultivable Rice seed endophytic community}

Six rice cultivars grown in the experimental fields of RDA (South Korea) were selected and harvested in August 2014. The population of the culturable bacterial endophytic community of rice seeds was assessed in five salt-tolerant cultivars and one salt-sensitive cultivar after surface sterilization and rehydration up to $10 \mathrm{~h}$. The population density ranges from 4.23 to $6.52 \log \mathrm{CFU} \mathrm{g}^{-1}$ fresh weight (Table 2). A total of 49 isolates with 18 distinct bacterial strains were identified from the internal tissues of rice seeds. The 16S rRNA gene identification of these cultures revealed that endophytes encompass members of 12 genera within the classes Alphaproteobacteria, Betaproteobacteria, Gammaproteobacteria, Actinobacteria and Firmicutes (Fig. 1). Several genera dominate the seed endosphere including Flavobacterium, Pantoea, Microbacterium, Xanthomonas, Kosakonia, Pseudomonas and Paenibacillus. There are common as well as cultivar-specific bacterial isolates from the different rice cultivars. Among the isolates, representatives of Flavobacterium 
Table 2 Bacterial population profiles in the seeds of salt-tolerant and salt-sensitive cultivars of Oryza sativa ssp. indica

\begin{tabular}{lllll}
\hline $\begin{array}{l}\text { Rice } \\
\text { cultivar }\end{array}$ & $\begin{array}{l}\text { Population } \\
\text { CFU g }\end{array}$ & $\begin{array}{l}\text { Gram (-) } \\
\%\end{array}$ & $\begin{array}{l}\text { Gram (+) } \\
\%\end{array}$ & $\begin{array}{l}\text { Cultivable } \\
\text { isolates }\end{array}$ \\
\hline IR29 & $5.46 \pm 0.09^{c}$ & 42.9 & 57.1 & 7 \\
FL478 & $5.31 \pm 0.02^{c}$ & 57.1 & 42.9 & 7 \\
IC27 & $6.31 \pm 0.04^{\mathrm{b}}$ & 100.0 & 0.0 & 4 \\
IC31 & $5.64 \pm 0.04^{c}$ & 90.0 & 10.0 & 10 \\
IC32 & $6.52 \pm 0.04^{\mathrm{a}}$ & 71.4 & 28.5 & 14 \\
IC37 & $4.24 \pm 0.04^{c}$ & 0.00 & 100.0 & 7 \\
\hline
\end{tabular}

Population is presented as means \pm SE (standard error) from three replicates. Means with the same letter are not statistically significant

sp. were isolated in all the rice cultivars, indicating that it is a common and possible dominant member of the bacterial endophytic community in rice seeds. Xanthomonas sp. and Microbacterium sp. were also isolated in four rice cultivars (IR29, FL478, IC31 and IC32, and IR29, FL478, IC31 and IC37, respectively) while Kosakonia sp. (IC27, IC31 and IC32) and Paenibacillus sp. (FL478 and IC32) were isolated in other rice cultivars. Highly identical type strains were isolated from the seed endosphere regardless of the rice host's physiological tolerance to salinity. The salt-sensitive rice cultivar, IR29, shares some common isolates with other salt-tolerant rice cultivars. Aside from Flavobacterium sp., Microbacterium sp. was also found in FL478, IC31 and IC37 while Xanthomonas sp. was isolated from FL478, IC31 and IC32. These similar type strains found in both the salt-sensitive and salt-tolerant cultivars might indicate other pertinent distinguishing factors that select cultivable bacterial communities in the rice cultivars other than the plant's physiological adaptation to salt stress.

Aside from the shared members of bacterial communities, there were also cultivar-specific isolates such as Rhizobium larrymoorei, Herbaspirillum huttiense and Curtobacterium citreum (Fig. 2). Potentially novel and unidentified bacterial isolates were also present, representing some members of Enterobacter and Pantoea. Most of the seed endophytes showed high 16S rRNA gene similarities isolated and/or sequenced from the rice phyllosphere, rhizosphere and endosphere, suggesting that these bacteria might be well adapted to the rice niche.

\section{Genetic diversity of seed bacterial endophytes}

To have an idea of the genetic relationship between the isolated endophytes from the different rice cultivars, BOX-PCR fingerprinting method was done (Additional file 1: Figure S2a). DNA fingerprinting via BOX-PCR generated diverse banding patterns with band size ranging from $100 \mathrm{bp}$ to over $3000 \mathrm{bp}$. For the 49 endophytic bacterial isolates, there were 10 distinct clusters that formed. Microbacterium strains formed a major cluster with three subclusters. Xanthomonas strains also formed a major cluster with two subclusters. The Paenibacillus, Kosakonia and Pantoea strains also formed their own distinct clusters while Flavobacterium major cluster was further divided into four subclusters (Additional file 1: Figure S2b).

\section{Plant growth promoting characteristics}

Different rice cultivars contain bacterial endophytes with multiple PGP characteristics (Additional file 2: Table S1).

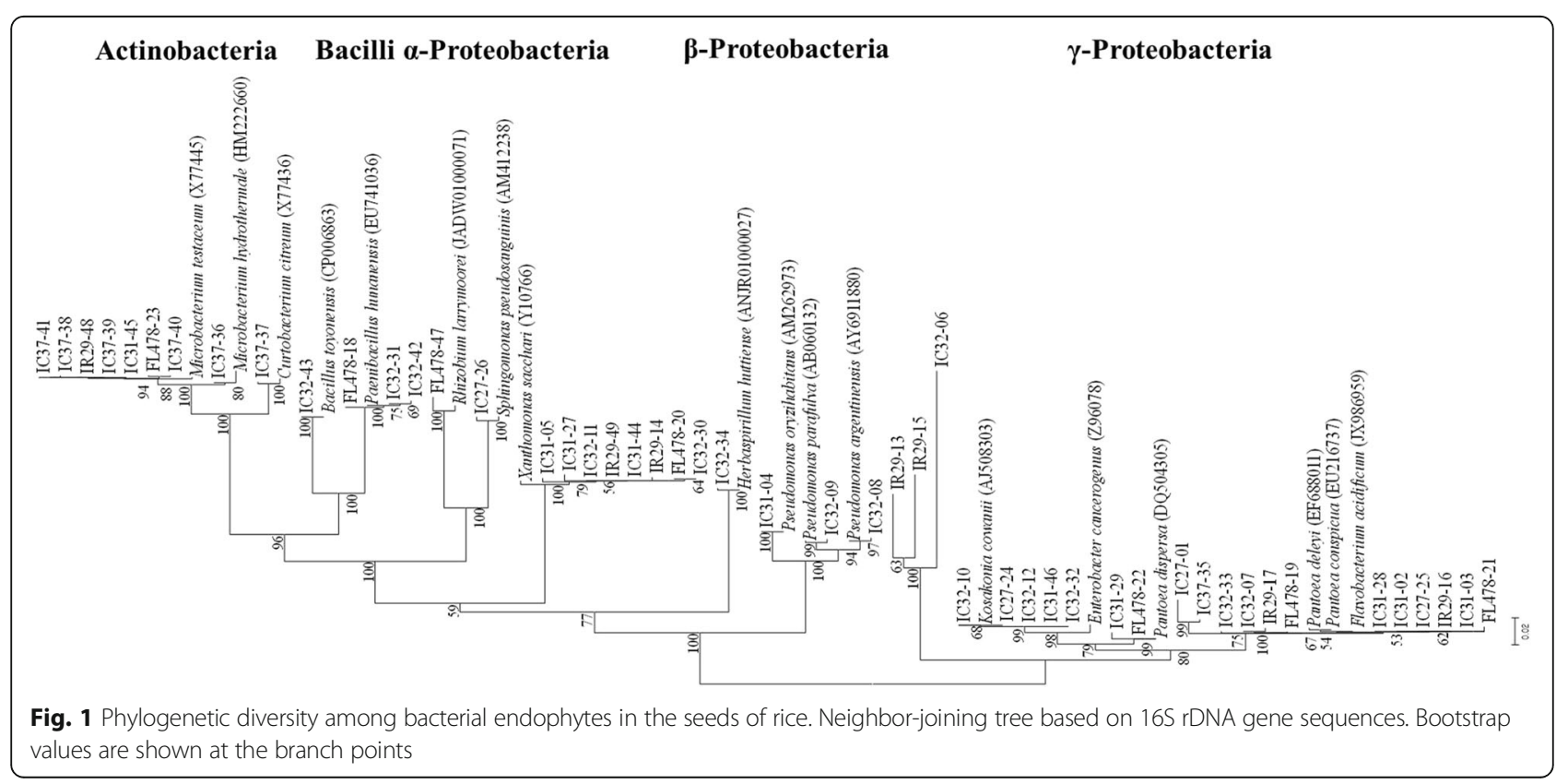




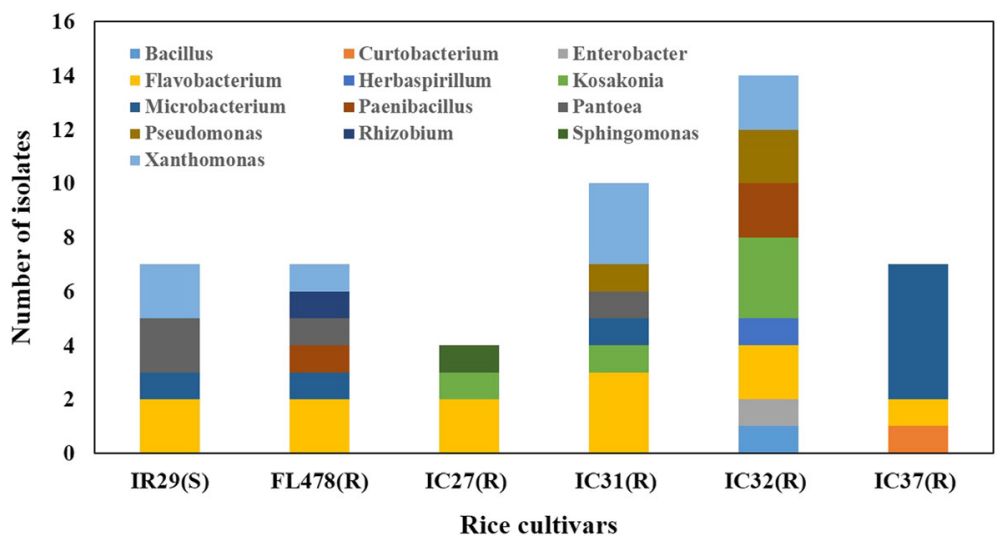

Fig. 2 The distribution of the different bacterial genera of endophytes isolated in the different rice cultivars. (S) - salt-sensitive cultivar; (R) salt-tolerant cultivars

All of the isolates were able to produce IAA in varying degrees from 2.4-66.0 $\mu \mathrm{g} \mathrm{ml} \mathrm{m}^{-1}$ in the presence of $\mathrm{L}$ tryptophan. ACC deaminase activity, an important PGP trait especially under stress conditions, was observed in 5 isolates $\left(470-7036 \mathrm{nmol} \alpha-\mathrm{KB} \mathrm{h}^{-1} \mathrm{mg}\right.$ protein $\left.^{-1}\right)$ that were cultured from different rice cultivars except for IR29 and IC27. ACCD bacteria include Pseudomonas sp. IC31-04, Paenibacillus sp. FL478-18, Kosakonia sp. IC32-32, Herbaspirillum sp. IC32-34 and Microbacterium sp. IC37-36; all of which belong to major groups commonly observed as plant growth promoting bacteria. Many of the bacterial isolates could fix nitrogen (33\%), solubilize phosphate $(73 \%)$ and produce siderophores $(65 \%)$ with varying degrees of metabolic activity in relation to these parameters (Table 3 ).

\section{Germination assay and early plant growth development} The effects of endophytic bacterial inoculation on rice seeds of the salt-sensitive cultivar IR29 were observed during germination under normal and $150 \mathrm{mM} \mathrm{NaCl}$ salt stress conditions as well as early seedling growth. Two strains, Microbacterium sp. IC37-36 and Flavobacterium sp. IR29-16 significantly and consistently increased shoot and root length and plant biomass. The detrimental effects of salt stress were observed on the germination rate and percentage of seeds, but inoculation with Flavobacterium sp. IC27-25, Flavobacterium sp. IC31-28 and Xanthomonas sp. IC31-27 significantly improved germination under salt stress conditions. Flavobacterium sp. strains isolated in the salt-sensitive cultivar were not able to significantly enhance germination parameters under salt stress conditions. Different rice cultivars contain an assemblage of bacterial endophytes that can promote germination and plant growth (Additional file 3: Figure S1a, b, c; Fig. 3).

\section{Endophytic adaptation of bacterial Endophytes from Rice seeds}

Of the functional traits and characteristics studied which are putatively necessary for endophytic lifestyle of bacterial isolates, the activities of pectinase, cellulase and catalase were observed from more than $92 \%$ of the bacterial isolates, suggesting the importance of these traits to endophytic lifestyle. Motility and oxidase activity were also observed in $41 \%$ and $71 \%$ of the isolates, respectively. All of the bacterial isolates were also capable of surviving and even thriving in $0.6 \mathrm{M}$ sucrose concentration while $96 \%$ were able to survive in $1.2 \mathrm{M}$ sucrose concentration. Most of the isolates can tolerate an induced salt stress of $4 \% \mathrm{NaCl}$ and higher. Only 3 isolates have the highest salt tolerance capable of growth in nutrient agar amended with $9 \% \mathrm{NaCl}$ (Additional file 4: Table S2; Table 3).

\section{Distinguishing characteristics of Rice seed bacterial endophytes}

Seed bacterial endophytes that belong to the same type strains possess similar PGP traits and physiological activities regardless of their isolation source, that is, whether they are isolated from the salt-sensitive or the salt-tolerant rice cultivar. Aside from the generally observed traits of seed endophytes, the bi-plot ordination of principal component analysis from 49 isolates reveals prominent distinguishing traits of several groups of rice seed bacterial endophytes. The ordination diagram using plant growth promoting traits (IAA, ACCD, phosphate solubilization) and physiological activities (salinity tolerance, osmotic tolerance and polymer-degrading enzymes) reveal three major groups occupying 3 quadrants (Fig. 4). Microbacterium sp. strains and Xanthomonas sp. strains isolated from the different rice cultivars are distinguished by their higher pectinase and cellulase activity. Siderophore production 


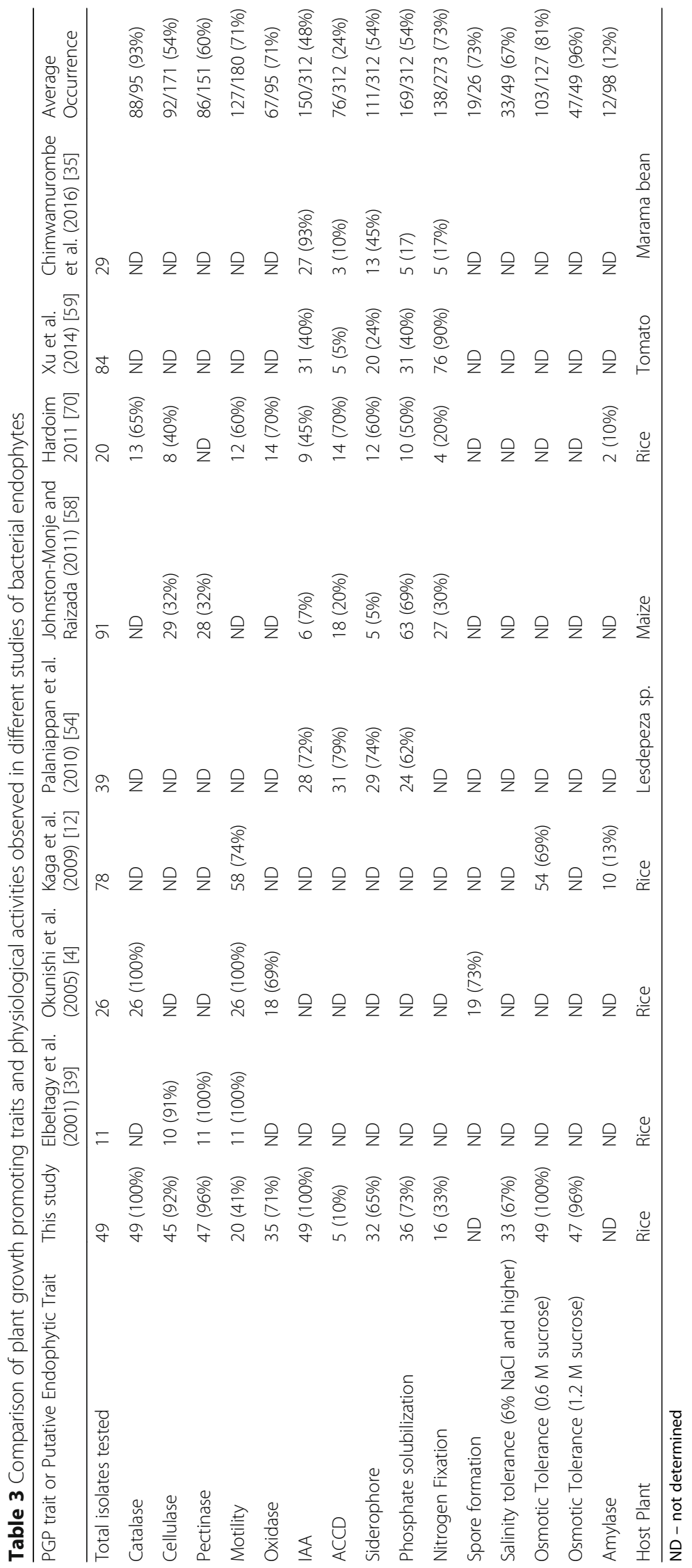




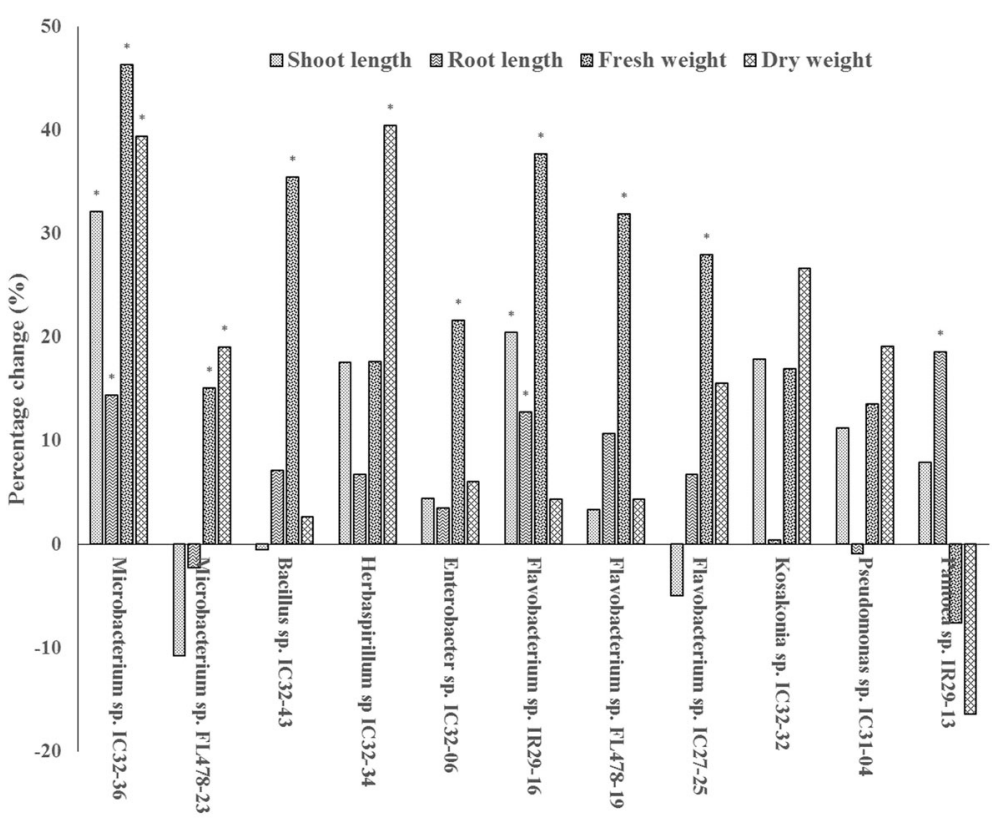

Bacterial Endophytes

Fig. 3 Percentage change of shoot length, root length, fresh weight and dry weight of IR29 seedling during early growth development after inoculation with selected endophytes. Asterisk (*) indicates statistically significant change over control at $P \leq 0.05$ ( $t$-test, SAS v9.4)

\section{Biplot (axes F1 and F2: $52.08 \%$ )}

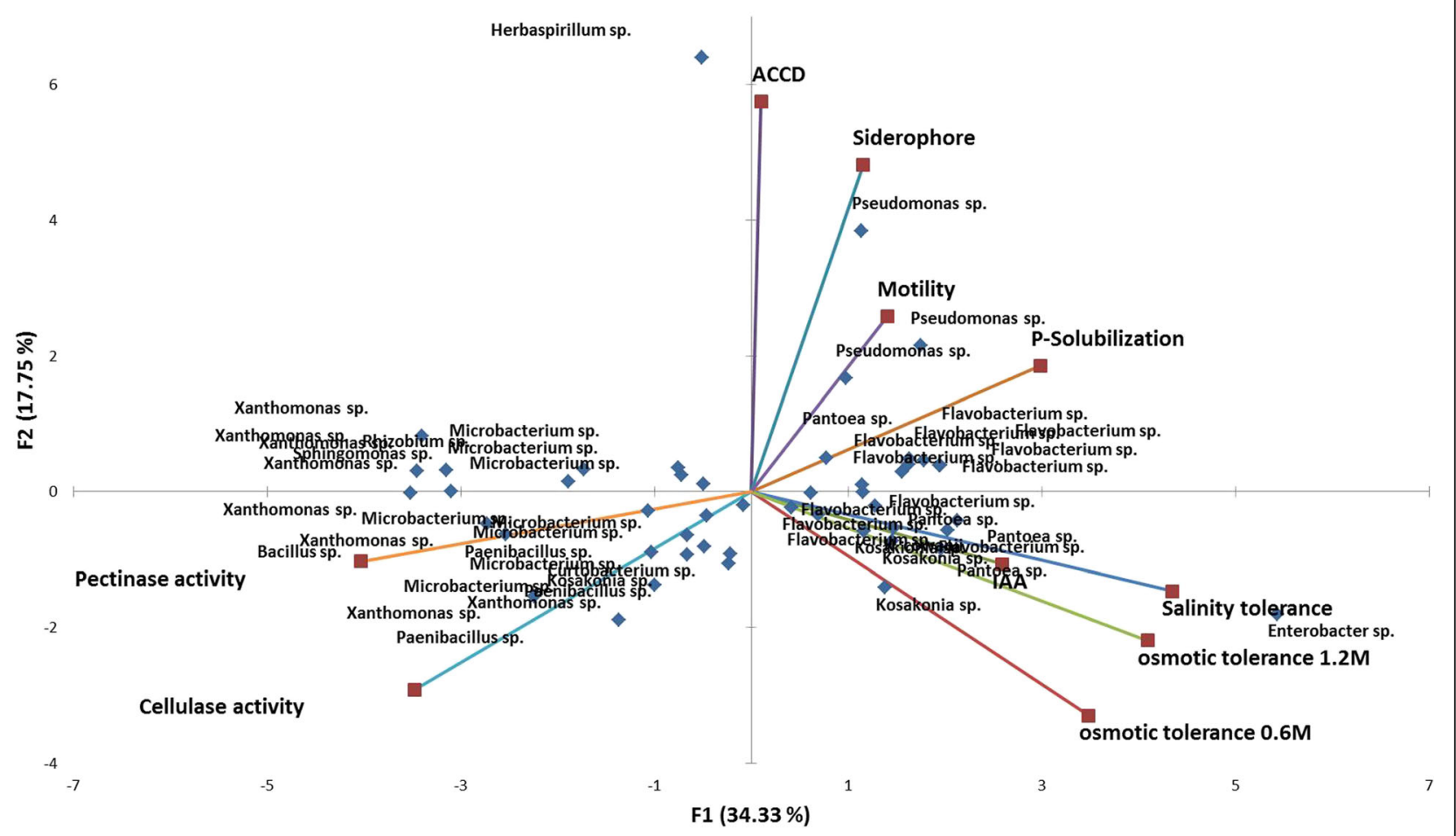

Fig. 4 Bi-plot ordination diagram of principal component analysis describing plant growth promoting traits and functional activities of 49 bacterial endophytes isolated from salt-sensitive and salt-tolerant rice cultivars 
distinguishes different representatives of Pseudomonas strains. Flavobacterium sp. strains are characterized as better phosphate solubilizers and IAA producers with higher osmotic and salinity tolerance. Strains from Kosakonia and Pantoea are featured as IAA producing, salt and osmotic tolerant endophytes. There is a significantly positive correlation between bacterial pectinase and cellulase activity. A positive correlation also exists for the ability of bacterial endophytes to tolerate salt and osmotic stress. Interestingly, IAA is moderately correlated with osmotic tolerance at $1.2 \mathrm{M}$ sucrose concentration.

Additional details in the PGP characters and physiological traits can also be observed in the different bacterial groups (Additional file 2: Table S1; Additional file 4: Table S2). Microbacterium sp. strains isolated in different rice cultivars do not produce siderophores and most do not have nitrogen fixing ability. Microbacterium sp. strains also tolerate to up to 4-6\% salt concentration and 1.2 $\mathrm{M}$ sucrose concentration. They all have catalase activity, low cellulase activity and moderate pectinase activity. Flavobacterium sp. strains produce a higher degree of IAA in the presence of tryptophan from 10 to $20 \mu \mathrm{g} \mathrm{ml}^{-1}$, some are nitrogen fixing bacteria, produce siderophores and solubilize phosphorus. They all have catalase activity and low cellulase and pectinase activity. Kosakonia sp., Pantoea spp. and Xanthomonas sp. strains generally produce smaller amounts of IAA ranging from 3 to $5 \mu \mathrm{g} \mathrm{ml}^{-1}$. They are mostly siderophore producers and phosphate solubilizers. Xanthomonas sp. strains show lower tolerance to salt stress where they can only survive up to $2 \%$ salt concentration. Osmotic tolerance varies where some strains have higher survival even at 1.2 M sucrose concentration. Xanthomonas sp. also shows very strong cellulase and pectinase activity. In this study, representatives of Actinobacteria and Bacilli do not produce siderophores.

\section{Discussion}

This study investigated plant growth promotion and physiological characteristics related to the endophytic lifestyle of culturable bacterial endophytes inhabiting the seeds of rice. There are relatively diverse groups of culturable bacterial endophytes of the rice seeds (Fig. 1, Fig. 2, Additional file 1: Figure S2b). Characterization of seed endophytes in terms of growth promotion activity showed that each rice cultivar possessed a plethora of endophytes with multiple plant growth promotion abilities (Additional file 2: Table S1), some of which could significantly enhance germination rate, germination percentage and plant growth of the rice seeds during early development (Additional file 3: Figure S1a, b c, Fig. 3). Characterization of physiological and functional traits related to endophytic lifestyle particularly in the seeds showed that majority of the endophytes have putative endophytic adaptations (Table 3;
Additional file 4: Table S2). On the other hand, several bacterial groups are distinguished by their PGP characters and physiological traits showing similar properties of strains that belong to the same bacterial type regardless of their isolation source (Fig. 4).

There are some bacterial groups such as Flavobacterium, Microbacterium, Xanthomonas, Pantoea and Kosakonia that were isolated in most of the rice cultivars. On the other hand, most of the isolated seed bacterial endophytes in this study were also observed in other studies on rice endophytes, though they were not isolated in all the cultivars studied, suggesting that these bacteria are widespread in the rice and that they are well adapted to the rice niche. Flavobacterium was detected in the leaves, roots and shoots [13, 36, 37]. Xanthomonas was detected in the leaves and seeds and acts as a biocontrol bacterium [36, 38]. Microbacterium, Pantoea, Enterobacter and Herbaspirillum were also commonly identified as endophytes in the rice host $[6,12,13,36,37,39,40]$. These major groups of bacteria were also seen as important members of the root endosphere [6]. Combining results of $16 \mathrm{~S}$ rRNA and BOX PCR show that the closest reference strains of the isolated bacteria (Microbacterium, Flavobacterium, Xanthomonas, Kosakonia, Paenibacillus) from the seed potentially belong to the same bacterial species, but may have genetic differences up to the subspecies level as they form subclusters within their own groups [41, 42]. Many of the bacterial isolates also have high similarities with reference strains that were originally isolated as rice-associated bacteria (Additional file 5: Table S3). This study indicates that rice seeds act as a vector for transmission of these rice associated bacterial endophytes colonizing different parts of the rice plant and finally recolonizing the seeds. These seed endophytes are also present in many of the rice cultivars irrespective of the hosts' genotype, physiological tolerance to salinity stress and phylogenetic relationship indicating that rice seeds are inhabited by potential core microbial communities found in other indica cultivars as well.

As bacterial endophytes colonize the plants, they may also be selectively maintained by their plant host due to their plant growth promoting traits or other beneficial properties. Rice seeds harbor an arsenal of bacterial endophytes with PGP traits that help during germination and early seedling development of seeds. Almost all of the ACCD bacteria isolated from the rice endosphere were able to promote growth during the early seedling development with Microbacterium sp. IC37-16 significantly enhancing germination and growth parameters. There were five ACCD positive isolates out of 49 in our study, but it seems to be a more prominent property of some endophytes as observed by other authors (Table 3). Beneficial bacteria containing ACCD aid in the development and plant growth by lowering ethylene levels primarily through cleaving ACC, the precursor of ethylene, 
to ammonia and $\alpha$-ketobutyrate which consequently reduces the extent of ethylene growth inhibition $[43,44]$. The advantageous effect of ACCD bacteria becomes prominent especially when the host plant experiences biotic or abiotic stress conditions. The process of deamination of ACC is a key plant growth promoting trait present in a wide range of bacteria such as Azospirillum, Burkholderia and Agrobacterium [45] and is essential for the promotion of growth and stress homeostasis regulation of the seedlings under saline conditions [46]. There is also an indication that ACCD is important during colonization as the production of ethylene is upregulated in plants during bacterial colonization especially by endophytes or pathogens [47]. Aside from ACCD, the phytohormone IAA is also a vital phytostimulator produced by bacteria. Indole-3acetic acid, the most commonly produced auxin, is a signaling molecule in both plant and microorganisms essentially acting as a reciprocal signaling molecule in plant-microbe interaction [48]. This study showed that IAA production is a prominent feature of rice seed endophytes as well as other endophytes (Table 3). Most of the isolates in this study are capable of producing IAA in varying amounts. This observation was also reviewed by Kim et al. [49] showing that plants are colonized by high numbers of IAA-producing bacteria. Inoculation of plants with IAA producing PGPB causes changes in the root architecture stimulating root hair formation and increasing the number and length of lateral and primary roots ultimately increasing root surface area for mineral uptake and root exudation [50, 51]. Flavobacterium sp. IR29-16 and other Flavobacterium sp. strains could have promoted significant growth particularly in the root length of plants through IAA production. A wild-type strain Pseudomonas putida GR12-2 producing $32.7 \mu \mathrm{g} \mathrm{mL}{ }^{-1}$ with $500 \mu \mathrm{g} \mathrm{mL}{ }^{-1}$ tryptophan amendment while a mutant strain producing only $2.0 \mu \mathrm{g} \mathrm{mL} \mathrm{m}^{-1}$ IAA were still capable of increasing root length and formation of adventitious roots in canola seeds and mung bean, respectively [52]. Rice plant is also a host to many nitrogenfixing endophytes isolated in the seeds, stems and roots [14] (Additional file 6: Figure S3). These diazotrophic bacteria, which are less likely to be found in soil, can also colonize the tissues of other gramineous plants forming small aggregates distributed in the plant body [53] yet does not necessarily form nodules [54]. Symbiotic biological nitrogen fixation between diazotrophic endophytes and tropical grasses including rice, show that some plants may obtain part of their nitrogen needs from such associations [55]. Siderophore production and phosphate solubilization may not have direct plant growth promotion effects during our study, but the fact that around $70 \%$ of the seed endophytes possess these traits suggest their importance during plant development. Pseudomonas strains from this study were distinguished by their high siderophore production.
Fluorescent pseudomonas have been studied as capable of colonizing various ecological niches and this is reflected by the high diversity of their iron uptake systems [56]. Endophytes producing siderophore especially the Pseudomonas strains in this study have a selective advantage over other bacteria and pathogens since they overcome competing organisms by depriving them of iron $[3,8]$. Rice plants were also observed to be colonized by consistent groups of siderophore-producing bacteria such as Pantoea in different plant parts and in different growth stages [57]. It has also been observed that some endophytes could migrate from the internal tissues to the external surface of the plants and even to the soil [58] and that several members of the seed endophytic community could colonize the rhizosphere and the surrounding soil [13]. During this time, phosphate solubilization may become important in the rhizosphere region of the roots.

Bacterial endophytes of rice seeds have prominent functional traits potentially important for their endophytic lifestyle and host adaptation [59]. Our study showed that majority of the seed endophytes are capable of producing cellulase (92\%) and pectinase (96\%) which was also observed by Elbetagy et al., [39] for rice endophytes. Some bacterial groups especially Microbacterium and Xanthomonas displayed higher secretion of cellulase and pectinase. Cellulase has been found to be widely distributed among Xanthomonas species and play a role in the degradation of plant cell walls [60]. Furthermore, plant-depolymerizing enzymes such as cellulase and pectinase are necessary during colonization and migration of endophytes from one location to another particularly in the degradation of the middle lamella [61] or through active penetration into the plants [39, 62, 63]. In Burkholderia sp. PsJN, cell wall-degrading endoglucanase, endopolygalacturonase and other associated enzymes were important in the entry into the root internal tissues of Vitis vinifera [64]. The same bacterial strain was also able to colonize the interior of young berries as well as the inflorescence organs such as grape stalks and immature berries primarily through the xylem vessels [65]. In addition, motility of bacteria may also be required for adhesion on plant surfaces [6]. In this study, motility is observed in $41 \%$ of the isolates, but was observed at $100 \%$ occurrence in other studies for rice endophytes [4, 39]. Kaga et al. [12] also showed that motility (74\% of their isolate) is more prominent in rice endophytes isolated in the shoots and phyllosphere compared to those in the roots, indicating the importance of motility in colonization and migration. Hardoim et al. [13] and Mano et al. [66] found that the seed endophytic community is more similar to the shoot community compared to the roots indicating that seed-borne endophytes rapidly and actively migrate from the spermosphere to the shoot endosphere. Such ability generally requires the production of plant-polymer degrading enzymes and motility or some sort for translocation. Catalase which helps detoxify ROS, 
can also be an essential component for successful survival of the colonizing endophyte during oxidative burst by plants [67]. Reactive oxygen species (ROS) are usually produced during endophytic colonization and pathogen invasion as a typical plant defense response. ROS-scavenging enzymes were also important in the endophytic colonization in the roots of rice as a means of counteracting the accumulation of ROS [68]. Catalase along with other ROS-scavenging enzymes was also found to be upregulated by Gluconacetobacter diazotrophicus during colonization and interactions with sugarcane following oxidative stress by the host plant [69]. Okunishi et al. [4] and Hardoim et al. [70] showed that catalase activity is present in many endophytes colonizing the rice plant as also observed in this study. The seed as an exclusive microhabitat may also require additional adaptation as it imposes a desiccating environment particularly in the mature seeds. In addition, during germination of seeds, osmotic pressure increases with the release of oligosaccharides and sugars necessitating the need for adaptation of seed endophytes to high osmotic pressure [12]. Furthermore, most of the isolates in this study can tolerate high osmotic stress which also points out that the seed can be a selective microhabitat to bacteria that can survive in the seed endosphere during seed maturation and seed germination. Flavobacterium, Kosakonia and Pantoea strains are notably salt tolerant and osmotic tolerant seed bacteria as presented in the results. There is also a significantly positive correlation between bacterial salt and osmotic tolerance. Surprisingly, the same bacterial strains capable of surviving in high osmotic stress can also tolerate high salinity conditions indicating dual adaptation as osmotic and salinity stress inflict the same initial limiting conditions [71-73] and these bacteria may have evolved the same mechanisms to combat these abiotic stresses. The almost ubiquitous activity of the polymer-degrading enzymes cellulase and pectinase as well as the ability to detoxify ROS through catalase by bacterial endophytes conform with metagenomic studies showing that these physiological characters are vital for endophytic competence. Comparative metagenomic analysis between endophytes, phytopathogens, rhizosphere bacteria and soil bacteria together with metagenomic analysis of the rice roots show that endophytes possess prominent features and metabolic processes important, if not required, for endophytic lifestyle including flagella or motility mechanisms, plant-polymer degrading enzymes, iron sequestration and storage and scavenging or detoxification of reactive oxygen species $[6,7]$.

\section{Conclusions}

The findings of the study not only support the use of seed bacterial endophytes as potential plant growth promoters but also give an overview of the general physiological features important for endophytic lifestyle, especially in the seeds. The study points out that the rice seed may selectively screen endophytes with physiological characteristics associated with tolerance to osmotic stress, ability to detoxify ROS and production of plant polymer-degrading enzymes. The study showed that rice seed bacterial endophytes possess physiological traits important for their survival in the seed endosphere along with plant growth promoting potential that enables them to modulate rice plant growth during germination and early seedling development. This study established that the seeds of rice plants are inhabited by several groups of bacteria isolated from many of the indica cultivars irrespective of the hosts' genotype, physiological adaptation to salt stress and phylogenetic lineages indicating the presence of core microbial communities transmitted via the seeds as they become common endophytes associated with rice. These groups also manifest prominent traits that distinguish them from other groups of bacteria and indicate key determinants for their success as endophytes in the seed microbiome. Further mechanisms of plant growth promotion as well as complete endophytic characterization and their responses to survival, colonization and maintenance in the plant host still need to be addressed to understand complex plant-biotic relationships.

\section{Additional files}

\begin{abstract}
Additional file 1: Figure S2. a Photograph of BOX PCR genomic fingerprints of rice seed endophytes resolved on an ethidium bromide stained agarose gel. 01, 14, 30, 31, 46 and 55: DNA ladder, 02-13: Flavobacterium sp. (IC27-01, IC31-02, IC31-03, IC32-07, IR29-16, IR29-17, FL478-19, FL478-21, IC27-25, IC31-28, IC32-33IC37-35,), 15-18: Pantoea sp. (IR29-13, IR29-15, FL478-22, IC31-29), 18-23: Kosakonia sp. (IC32-10, IC32-12, IC27-24, IC32-32, IC32-46), 24-26: Paenibacillus sp. (FL478-18, IC32-31, IC32-42), 27-29: Pseudomonas sp. (IC32-08, IC31-04, IC32-09), 32-39: Xanthomonas sp. (IC31-05, IC32-11, IR29-14, FL478-20, IC31-27, IC32-30,IC31-44, IR29-49), 40: Enterobacter sp. 34, 41: Herbaspririllum sp. 34, 42: Rhizobium sp. 47, 43: Sphingomonas sp. 26, 44: Bacillus sp. 43, 45: Curtobacterium sp. 37, 47-54: Microbacterium sp. (IC37-36, FL478-23, IC37-38,IC37-39, IC37-40, IC37-41, IC31-45, IR29-48). b Cluster analysis of BOX PCR genomic fingerprints of 49 endophytic bacteria isolated from the seed endosphere of indica rice cultivars. The dendrogram was constructed using SPSS Statistics Version 20 using heirarchichal cluster analysis. (ZIP $210 \mathrm{~kb}$ )
\end{abstract}

Additional file 2: Table S1. PGP traits of bacterial endophytes in rice seeds. (DOCX $66 \mathrm{~kb}$ )

Additional file 3: Figure S1. a Percentage change in germination parameters of IR29 seeds after inoculation with endophytes from Actinobacteria, Bacilli, a- and $\beta$-Proteobacteria. b Percentage change in germination parameters of IR29 seeds after inoculation with endophytes from Flavobacterium and Kosakonia. c Percentage change in germination parameters of IR29 seeds after inoculation with endophytes from Pantoea, Pseudomonas and Xanthomonas. (ZIP $262 \mathrm{~kb}$ )

Additional file 4: Table S2. Functional traits and metabolic activity associated to endophytic adaptation of bacterial endophytes in seeds of rice. (DOCX $25 \mathrm{~kb}$ )

Additional file 5: Table S3. Information on the seed bacterial endophytes isolated from the different rice cultivars showing accession number, closest type strain and closest rice associated bacteria. (XLSX 39 kb) 
Additional file 6: Figure S3. Amplification of the nifH gene of seed bacterial endophytes showing nested PCR product with $\sim 317$ bp fragment as amplified with nifHFor and nifHRev primer set. (JPEG $71 \mathrm{~kb}$ )

\begin{abstract}
Abbreviations
ACC: 1-aminocyclopropane-1-carboxylate; ACCD: 1-aminocyclopropane-1carboxylate deaminase; ANOVA: Analysis of Variance; CAS: Chrome azurol S medium; CFU: Colony forming unit; CMC: Carboxymethylcellulose; dS m ${ }^{-1}$ : DeciSiemens per meter; FL478: Moderately salt-tolerant cultivar; IR6696463R-178-1-1; IAA: Indole-3-acetic acid; IC27: Moderately salt-tolerant cultivar; CSR 28; IC31: Moderately salt-tolerant cultivar; IR55179-3B-11-3; IC32: Moderately salt-tolerant cultivar; IR58443-6B-10-3; IC37: Highly salttolerant cultivar; IRRI154; IR29: Salt sensitive rice cultivar; IRRI: International Rice Research Institute, Philippines; LSD: Least significant difference; NBRIPBPB: National Botanical Research Institute Phosphate-bromophenol blue medium; OD: Optical density; PCA: Principal component analysis; PCR: Polymerase chain reaction; PGP: Plant growth promotion; PGPR: Plant growth promoting rhizobacteria; R2A: Reasoner's 2A medium; RDA: Rural Development Administration, South Korea; ROS: Reactive oxygen species; rpm: Revolutions per minute; $\mathrm{a}-\mathrm{KB}$ : Alpha ketobutyrate
\end{abstract}

\section{Acknowledgements}

Authors acknowledge the help of Parthiban Subramanian and Selvakumar Gopal for assisting in the experimental set-up and suggestions on the improvement of the manuscript.

\section{Funding}

This research was supported by Basic Research Program through the National Research Foundation of Korea (NRF) funded by the Ministry of Education, Science and Technology (2015R1A2A1A05001885).

\section{Availability of data and materials}

All data generated or analyzed during this study are included in this article (and its supplementary information files) or are available from the corresponding author on reasonable request.

\section{Authors' contributions}

DW and TS conceived and designed the experiments; DW - performed the experiment and analyzed the data; DW and TS wrote the manuscript; MM and YKK - critical revision of the manuscript; DW, KK, YKK, YK and TS - manuscript preparation and editing. All authors read and approved the final manuscript.

\section{Ethics approval and consent to participate}

Not applicable

\section{Consent for publication}

Not applicable

\section{Competing interests}

The authors declare that they have no competing interests.

\section{Publisher's Note}

Springer Nature remains neutral with regard to jurisdictional claims in published maps and institutional affiliations.

\section{Author details \\ 'Department of Environmental and Biological Chemistry, College of Agriculture, Life and Environmental Sciences, Chungbuk National University, Cheongju, Chungbuk 28644, Republic of Korea. ${ }^{2}$ Temasek Life Sciences Laboratory, Biomaterials and Biocatalyst, National University of Singapore, Singapore, Singapore.}

Received: 2 May 2017 Accepted: 18 October 2017

Published online: 26 October 2017

\section{References}

1. Hardoim PR, van Overbeek LS, van Elsas JD. Properties of bacterial endophytes and their proposed role in plant growth. Trends Microbiol. 2008;16(10):463-71.
2. Reinhold-Hurek B, Hurek T. Living inside plants: bacterial endophytes. Curr Opin Plant Biol. 2011;14(4):435-43.

3. Compant S, Clément C, Sessitsch A. Plant growth-promoting bacteria in the rhizo-and endosphere of plants: their role, colonization, mechanisms involved and prospects for utilization. Soil Biol Biochem. 2010;42(5):669-78.

4. Okunishi S, Sako K, Mano H, Imamura A, Morisaki H. Bacterial flora of endophytes in the maturing seed of cultivated rice (Oryza sativa). Microbes Environ. 2005;20(3):168-77.

5. Truyens S, Weyens N, Cuypers A, Vangronsveld J. Bacterial seed endophytes: genera, vertical transmission and interaction with plants. Environ Microbio Rep. 2015;7(1):40-50

6. Sessitsch A, Hardoim P, Döring J, Weilharter A, Krause A, Woyke T, Mitter B, Hauberg-Lotte L, Friedrich F, Rahalkar M. Functional characteristics of an endophyte community colonizing rice roots as revealed by metagenomic analysis. Mol Plant-Microbe Interact. 2012;25(1):28-36.

7. Hardoim PR, Van Overbeek LS, Berg G, Pirttilä AM, Compant S, Campisano A Döring $M$, Sessitsch A: The hidden world within plants: ecological and evolutionary considerations for defining functioning of microbial endophytes. Microbiol Mol Biol R 2015, 79(3):293-320.

8. Compant S, Duffy B, Nowak J, Clément C, Barka EA. Use of plant growthpromoting bacteria for biocontrol of plant diseases: principles, mechanisms of action, and future prospects. Appl Environ Microb. 2005;71(9):4951-9.

9. Höflich G, Wiehe W, Kühn G. Plant growth stimulation by inoculation with symbiotic and associative rhizosphere microorganisms. Cell Mol Life Sci. 1994;50(10):897-905.

10. Kloepper JW, Zablotowicz RM, Tipping EM, Lifshitz R. Plant growth promotion mediated by bacterial rhizosphere colonizers. In: Keister DL, Cregan PB (Eds.). The rhizosphere and plant growth. The Netherlands: Kluwer Academic Publishers; 1991. p. 315-26.

11. Rosenblueth M, Martínez-Romero E. Bacterial endophytes and their interactions with hosts. Mol Plant-Microbe Interact. 2006;19(8):827-37.

12. Kaga H, Mano H, Tanaka F, Watanabe A, Kaneko S, Morisaki H. Rice seeds as sources of endophytic bacteria. Microbes Environ. 2009;24(2):154-62.

13. Hardoim PR, Hardoim CC, Van Overbeek LS, Van Elsas JD. Dynamics of seedborne rice endophytes on early plant growth stages. PLoS One. 2012;7(2):e30438.

14. Mano $\mathrm{H}$, Morisaki $\mathrm{H}$. Endophytic bacteria in the rice plant. Microbes Environ. 2008;23(2):109-17

15. Hardoim PR, Andreote FD, Reinhold-Hurek B, Sessitsch A, van Overbeek LS, van Elsas JD. Rice root-associated bacteria: insights into community structures across 10 cultivars. FEMS Microbiol Ecol. 2011;77(1):154-64.

16. Walia H, Wilson C, Condamine P, Liu X, Ismail AM, Zeng L, Wanamaker SI, Mandal J, Xu J, Cui X. Comparative transcriptional profiling of two contrasting rice genotypes under salinity stress during the vegetative growth stage. Plant Physiol. 2005;139(2):822-35.

17. Hurek T, Reinhold-Hurek B, Van Montagu M, Kellenberger E. Root colonization and systemic spreading of Azoarcus sp. strain BH72 in grasses. J Bacteriol. 1994; 176(7):1913-23.

18. Miché L, Balandreau J. Effects of rice seed surface sterilization with hypochlorite on inoculated Burkholderia vietnamiensis. Appl Environ Microb. 2001;67(7):3046-52.

19. DeLong EF. Archaea in coastal marine environments. Proc Natl Acad Sci USA. 1992:89:5685-5689.

20. Kim O-S, Cho Y-J, Lee K, Yoon S-H, Kim M, Na H, Park S-C, Jeon YS, Lee J-H, Yi H. Introducing EzTaxon-e: a prokaryotic 165 rRNA gene sequence database with phylotypes that represent uncultured species. Int I Syst Evol Micr. 2012;62(3):716-21.

21. Tamura K, Stecher G, Peterson D, Filipski A, Kumar S. MEGA6: molecular evolutionary genetics analysis version 6.0. Mol Biol Evol. 2013;30(12):2725-9.

22. Thompson JD, Higgins DG, Gibson TJ. CLUSTAL W: improving the sensitivity of progressive multiple sequence alignment through sequence weighting, position-specific gap penalties and weight matrix choice. Nucleic Acids Res. 1994;22(22):4673-80.

23. Jukes TH, Cantor CR: Evolution of protein molecules. Mammalian Protein Metabolism academic press, New York 1969, 3(21):132.

24. Saitou N, Nei M. The neighbor-joining method: a new method for reconstructing phylogenetic trees. Mol Biol Evol. 1987;4(4):406-25.

25. Felsenstein J. Confidence limits on phylogenies: an approach using the bootstrap. Evolution. 1985:783-91.

26. Bano N, Musarrat J. Characterization of a new Pseudomonas aeruginosa strain NJ-15 as a potential biocontrol agent. Curr Microbiol. 2003;46(5):324-8. 
27. Mehta S, Nautiyal CS. An efficient method for qualitative screening of phosphate-solubilizing bacteria. Curr Microbiol. 2001;43(1):51-6.

28. Alexander D, Zuberer D. Use of chrome azurol $\mathrm{S}$ reagents to evaluate siderophore production by rhizosphere bacteria. Biol Fert Soils. 1991;12(1):39-45.

29. Penrose DM, Glick BR. Methods for isolating and characterizing ACC deaminase-containing plant growth-promoting rhizobacteria. Physiol Plantarum. 2003;118(1):10-5.

30. Honma M, Shimomura T. Metabolism of 1-aminocyclopropane-1-carboxylic acid. Agric Biol Chem. 1978;42(10):1825-31.

31. Soares RA, Roesch LFW, Zanatta G, de Oliveira Camargo FA, Passaglia LM. Occurrence and distribution of nitrogen fixing bacterial community associated with oat (Avena sativa) assessed by molecular and microbiological techniques. Appl Soil Ecol. 2006;33:221-34

32. Tittsler RP, Sandholzer LA. The use of semi-solid agar for the detection of bacterial motility. J Bacteriol. 1936;31(6):575-80.

33. Kasana RC, Salwan R, Dhar H, Dutt S, Gulati A. A rapid and easy method for the detection of microbial cellulases on agar plates using Gram's iodine. Curr Microbiol. 2008;57(5):503-7.

34. Jacob N, Niladevi K, Anisha G, Prema P. Hydrolysis of pectin: an enzymatic approach and its application in banana fiber processing. Microbiol Res. 2008;163(5):538-44.

35. Naik P, Raman G, Narayanan KB, Sakthivel N. Assessment of genetic and functional diversity of phosphate solubilizing fluorescent pseudomonads isolated from rhizosphere soil. BMC Microbiol. 2008;8:230.

36. Ferrando L, Mañay JF, Scavino AF. Molecular and culture-dependent analyses revealed similarities in the endophytic bacterial community composition of leaves from three rice (Oryza sativa) varieties. FEMS Microbiol Ecol. 2012;80(3):696-708.

37. Sun L, Qiu F, Zhang X, Dai X, Dong X, Song W. Endophytic bacterial diversity in rice (Oryza sativa L.) roots estimated by $16 \mathrm{~S}$ rDNA sequence analysis. Microbial Ecol. 2008;55(3):415-24.

38. Fang $Y$, Lin $H$, Wu L, Ren D, Ye W, Dong G, Zhu L, Guo L. Genome sequence of Xanthomonas sacchari R1, a biocontrol bacterium isolated from the rice seed. J Biotechnol. 2015;206:77-8.

39. Elbeltagy A, Nishioka K, Sato T, Suzuki H, Ye B, Hamada T, Isawa T, Mitsui H, Minamisawa K. Endophytic colonization and in planta nitrogen fixation by a Herbaspirillum sp. isolated from wild rice species. Appl Environ Microb. 2001;67(11):5285-93.

40. Zhang X-X, Gao J-S, Cao Y-H, Ma X-T, He J-Z. Long-term rice and green manure rotation alters the endophytic bacterial communities of the rice root. Microb Ecol. 2013;66(4):917-26.

41. Louws FJ, Schneider M, de Bruijn FJ. Assessing genetic diversity of microbes using repetitive sequencebased PCR (rep-PCR) In: Toranzos G, editor. Nucleic acid amplification methods for the analysis of environmental samples. Lancaster: Technomic Publishing Co; 1996. p. 63-94.

42. Ishii S, Sadowsky MJ. Applications of the rep-PCR DNA fingerprinting technique to study microbial diversity, ecology and evolution. Environ Microbiol. 2009;11:733-40.

43. Glick BR, Penrose DM, Li J. A model for the lowering of plant ethylene concentrations by plant growth-promoting bacteria. J Theor Biol. 1998; 190(1):63-8.

44. Glick BR, Todorovic B, Czarny J, Cheng Z, Duan J, McConkey B. Promotion of plant growth by bacterial ACC deaminase. Cr Rev Plant Sci. 2007;26(5-6):227-42.

45. Blaha D, Prigent-Combaret C, Mirza MS, Moënne-Loccoz Y. Phylogeny of the 1-aminocyclopropane-1-carboxylic acid deaminase-encoding gene acdS in phytobeneficial and pathogenic Proteobacteria and relation with strain biogeography. FEMS Microbiol Ecol. 2006;56(3):455-70.

46. Sgroy V, Cassán F, Masciarelli O, Del Papa MF, Lagares A, Luna V. Isolation and characterization of endophytic plant growth-promoting (PGPB) or stress homeostasis-regulating (PSHB) bacteria associated to the halophyte Prosopis strombulifera. Appl Microbiol Biotech. 2009;85(2):371-81.

47. Iniguez AL, Dong Y, Carter HD, Ahmer BM, Stone JM, Triplett EW. Regulation of enteric endophytic bacterial colonization by plant defenses. Mol PlantMicrobe Interact. 2005;18(2):169-78.

48. Spaepen S, Vanderleyden J. Auxin and plant-microbe interactions. Cold Spring Harb Perspect Biol. 2011;3(4):a001438.

49. Kim YC, Leveau J, Gardener BBM, Pierson EA, Pierson LS, Ryu C-M. The multifactorial basis for plant health promotion by plant-associated bacteria. Appl Environ Microb. 2011;77(5):1548-55.

50. Duca D, Lorv J, Patten CL, Rose D, Glick BR. Indole-3-acetic acid in plantmicrobe interactions. Antonie Van Leeuwenhoek. 2014;106(1):85-125.
51. Vessey JK. Plant growth promoting rhizobacteria as biofertilizers. Plant Soil. 2003;255(2):571-86.

52. Patten $\mathrm{CL}$, Glick BR. Role of pseudomonas putida indole acetic acid in development of the host plant root system. Appl Environ Microbiol. 2002;68(8):3795-801.

53. Reinhold-Hurek B, Hurek T. Life in grasses: diazotrophic endophytes. Trends Microbiol. 1998;6(4):139-44.

54. López-López A, Rogel M, Ormeno-Orrilo E, Martinez-Romero J, MartinezRomero E. Phaseolus vulgaris seed-borne endophytic community with novel bacterial species such as Rhizobium endophyticum. Syst Appl Microbiol. 2010;33(6):322-7.

55. James E. Nitrogen fixation in endophytic and associative symbiosis. Field Crop Res. 2000;65(2):197-209.

56. Cornelis P, Matthijs S. Diversity of siderophore-mediated iron uptake systems in fluorescent pseudomonads: not only pyoverdines. Environ Microbiol. 2002;4(12):787-98.

57. Loaces I, Ferrando L, Scavino AF. Dynamics, diversity and function of endophytic siderophore-producing bacteria in rice. Microbial Ecol. 2011;61(3):606-18.

58. Johnston-Monje D, Raizada MN. Conservation and diversity of seed associated endophytes in Zea across boundaries of evolution, ethnography and ecology. PLoS One. 2011:6(6):e20396.

59. Rosenblueth et al. Seed bacterial endophytes: common genera, seed-toseed variability and their possible role in plants XXVIII international horticultural congress on science and horticulture for people (IHC2010): international symposium on environmental, edaphic, and genetic factors affecting plants, seeds and Turfgrass. In: ISBN 978-90-66055-75-9; 2012.

60. Studholme DJ, Wasukira A, Paszkiewicz K, Aritua V, Thwaites R, Smith J, Grant M. Draft genome sequences of Xanthomonas sacchari and two banana-associated Xanthomonads reveal insights into the Xanthomonas group 1 clade. Genes. 2011;2(4):1050-65.

61. Reinhold-Hurek B, Maes T, Gemmer S, Van Montagu M, Hurek T. An endoglucanase is involved in infection of rice roots by the not-cellulosemetabolizing endophyte Azoarcus sp. strain BH72. Mol Plant-Microbe Interact. 2006;19(2):181-8.

62. James EK, Gyaneshwar P, Mathan N, Barraquio WL, Reddy PM, lannetta PP, Olivares FL, Ladha JK. Infection and colonization of rice seedlings by the plant growth-promoting bacterium Herbaspirillum seropedicae Z67. Mol Plant-Microbe Interact. 2002;15(9):894-906.

63. Lodewyckx C, Vangronsveld J, Porteous F, Moore ER, Taghavi S, Mezgeay M, Lelie Dv d. Endophytic bacteria and their potential applications. Cr Rev Plant Sci. 2002;21(6):583-606.

64. Compant S, Reiter B, Sessitsch A, Nowak J, Clément C, Barka EA. Endophytic colonization of Vitis vinifera $\mathrm{L}$. by plant growth-promoting bacterium Burkholderia sp. strain PsJN. Appl Environ Microb. 2005;71(4):1685-93.

65. Compant S, Kaplan H, Sessitsch A, Nowak J, Ait Barka E, Clément C. Endophytic colonization of Vitis vinifera $\mathrm{L}$. by Burkholderia phytofirmans strain PsJN: from the rhizosphere to inflorescence tissues. FEMS Microbiol Ecol. 2008;63(1):84-93.

66. Mano H, Tanaka F, Nakamura C, Kaga H, Morisaki H. Culturable endophytic bacterial flora of the maturing leaves and roots of rice plants (Oryza sativa) cultivated in a paddy field. Microbes Environ. 2007;22(2):175-85.

67. Taghavi S, Van Der Lelie D, Hoffman A, Zhang Y-B, Walla MD, Vangronsveld J, Newman L, Monchy S. Genome sequence of the plant growth promoting endophytic bacterium Enterobacter sp. 638. PLoS Genet. 2010;6(5):e1000943.

68. Alquéres S, Meneses C, Rouws L, Rothballer M, Baldani I, Schmid M, Hartmann A. The bacterial superoxide dismutase and glutathione reductase are crucial for endophytic colonization of rice roots by Gluconacetobacter diazotrophicus PAL5. Mol Plant-Microbe Interact. 2013;26(8):937-45.

69. Lery LM, Hemerly AS, Nogueira EM, von Krüger WM, Bisch PM. Quantitative proteomic analysis of the interaction between the endophytic plantgrowth-promoting bacterium Gluconacetobacter diazotrophicus and sugarcane. Mol Plant-Microbe Interact. 2011;24(5):562-76.

70. Hardoim PR: Bacterial endophytes of rice-their diversity, characteristics and perspectives: university library Groningen; 2011.

71. Csonka LN. Physiological and genetic responses of bacteria to osmotic stress. Microbiol Rev. 1989;53(1):121-47.

72. Wood JM. Bacterial responses to osmotic challenges. J Gen Physiol. 2015;145(5):381-8.

73. Xiong L, Schumaker KS, Zhu JK. Cell signaling during cold, drought, and salt stress. Plant Cell. 2002;14(suppl):S165-83. 